reactors and documented the superficiality and incompetence of AEC licensing of nuclear power plants". Quoting directly from the report, Nader said that safety problems are "besieging" American nuclear power plants, and the level of safety of such power plants is "an unanswered question".

Most of the detailed examples of safety problems cited by Nader involve engineering defects which came to light after the plants were built. For example, he quoted a finding of the task force that five plants built by General Electric Company had, among other defects, broken hangar bolts, no lock nuts and improper bolts, and the deficiencies "could negate operability of the ECCS (the emergency core cooling system, which is supposed to flood the reactor core with water if the primary coolant is lost in an accident)".

Nader ended up by suggesting that the joint committe should dissolve itself because of its poor track record. But that suggestion did not go down too well with the members of that august body, and a verbal battle broke out. In particular, Mike McCormack, who was a nuclear chemist before becoming a politician, said that Nader's statements "revealed very profound ignorance of the whole subject".

Meanwhile, in Britain, the former General Manager of the US Atomic Energy Commission, Professor C. I. Wilson, listed the hazards of American light water reactors, in order of importance. First and foremost, he said in an interview with the Times, are doubts about the inherent safety of the light water pressure vessel containing the nuclear core, which could melt into "a radioactive puddle" in the event of a failure. Reactors of this type, he said, were "most unattractive animals to have as neighbors". And, if they really have to be built, he would rather see them 500 feet underground, in a sound geological formation.
An adviser on energy to the United States government, and a faculty member of the Massachusetts Institute of Technology, Professor Wilson went on to voice concern about nuclear reactors in general. After pressure vessel failure, the second most alarming prospect in his book is the production of large quantities of highly toxic material. The technology for handling the plutonium generated in breeder reactors is in its infancy, Professor Wilson said. Plutonium is the most toxic material known: AEC standards allow only half of one millionth of a gram to be absorbed by a person in a lifetime, but reactors are producing as much as 250 $\mathrm{kg}$ of plutonium each.

$\mathrm{He}$ is also anxious about the safety of future generations who are being left with a legacy of stored radioactive fission products. Although, he added, he has a degree of confidence that long term handling of the waste can be arranged safely.

\title{
correspondence
}

\section{Energy strategy}

SrR,-I am sorry that travel has kept me from responding earlier to your provocative leader 'A Broader Debate on Energy’ (Nature, 246, 179; 1973).

In kindly discussing my monograph, 'World Energy Strategies: Facts, Issues, and Options', you attempt what I did not dare-a brief summary of an extremely complex argument-and thereby, I fear, distort its thrust and substance.

I do not "sec coal as the short and medium term solution to the energy problem", but as part of a diverse strategy stressing conservation and "unconventional" sources. Much better ways to mine, burn, and convert coal can help us to bridge to a sustainable energy economy, but are not a panacea.

You suggest that the paper ignores the social costis of coal. Careful reading does not support your view. Full weight is given to these high costs, which can be reduced but not eliminated. My "naive reference to a. . . deep mine which 'is said to use every kind of ... precaution yet is still profitable' " is not an attempt to "let (coal) off the social hook", but a criticism of many operators for refusing, on economic grounds, to enforce precautions already known.

You refer to my "biased point of view prepared to give coal the benefit of every doubt, nuclear energy the benefit of none". In fact, when all I knew about fission was what its proponents told me, I welcomed fission as a 'clean' alternative to coal. I am now prepared to give fission technologists full marks for zeal and cleverness, partial (and, in the USA, often undescrved) marks for diligence, and zero marks for recognising crucial gaps between intention and performance.

Many scientists far more distinguished than I are coming to appreciate the impact of human fallibility on a technology in which "no acts of God can be permitted" (Alfvén). Pugwash/ Aulanko is one sign of a profound shift of opinion now underway. Another: last autumn, of 20-odd senior energy cxperts whom I saw in Washington, all were worried by fission and frightened by fast breeders; two-thirds wanted to go promptly to a fission-free economy. A year earlier, nearly all had been cnthusiastic fission advocates.

A summary of recent convergence amongst sophisticated energy strategists cannot shrink from heterodoxy. It must attempt a thoughtful analysis of safeguards, safety, and waste disposal as they might be practised in the real world, not merely as they are designed in blueprints. References to Frisch's familiar paper are no substitute for the careful study that these issucs deserve.

I could not agree more with your call for broad, holistic, up-to-date public and professional debate on Britain's long-term energy future. I am sure that many will join me in offering our help if you, Sir, are prepared to use your influence in practical initiatives to this end.

Yours faithfully, AMORY B. Lovins

British Representative,

Friends of the Earth Inc

c/o Friends of the Earth Ltd,

9, Poland Street,

London $W 1 \mathrm{~V} 3 \mathrm{DG}$

\section{Bomb disposal}

SIR,--Mr Davidson's suggestion of using liquid nitrogen for bomb disposal purposes (Nature, 246, 548; 1973) is a technique invented by the Royal Fngineers thirty years ago. The Germans had developed their ' $Y$ ' fuse which used mercury switches as an anti-handling device. The counter-tactic developed was to freeze the mercury in the fuse and then remove and dispose of the device. Liquid nitrogen, liquid oxygen, and a mixture of solid $\mathrm{CO}_{2}$ and methanol were all used as refrigerants. The technique was completely successful. Plus ca change. ....

Yours faithfully.

$$
\text { P. R. W. WebB }
$$

Office of Science and Technology,

Department of Industry.

Trade and Commerce

Ottawa 